\title{
O SILÍCIO POTENCIALIZA O DESEMPENHO FOTOQUÍMICO EM FOLHAS DE ARROZ
}

\section{Sandro Dan Tatagiba ${ }^{1}$ \\ Anelisa de Figueiredo Peloso ${ }^{2}$ \\ Fabrício Ávila Rodrigues ${ }^{3}$}

\begin{abstract}
Resumo: Objetivou-se com este trabalho investigar o efeito do silício (Si) sobre os parâmetros de trocas gasosas da fotossíntese [assimilação líquida de CO2 (A), condutância estomática (gs) e concentração interna de CO2 (Ci)], dos parâmetros de fluorescência da clorofila (Chl) a \{fluorescência mínima (FO), fluorescência máxima (Fm), eficiência quântica máxima da fotoquímica (Fv/Fm), coeficiente de extinção fotoquímica (qp), rendimento da fotoquímica [Y(II)], rendimento de dissipação de energia regulado [Y(NPQ)] e o rendimento das perdas de dissipação não reguladas $[Y(N O)]\}$, bem como sobre as concentrações de pigmentos cloroplastídicos em plantas de arroz cultivadas em solução nutritiva contendo 0 ou $2 \mathrm{mmol}$ de Si (-Si ou +Si nas plantas, respectivamente). Os resultados do presente estudo indicam que o Si contribuiu para o desempenho fotoquímico em folhas de arroz, o qual, esteve associado a aumentos em Fv/Fm, qp, $Y(I I)$. Nas plantas supridas com Si também houve incrementos em A e nos pigmentos fotossintéticos. Dessa forma, podemos concluir que o suprimento de Si pode ser utilizado como uma estratégia de mitigação para aumentar a produtividade primária em arroz.
\end{abstract}

Palavras-chave: Fluorescência de imagem da clorofila a; Fotossíntese; Oryza sativa; Trocas gasosas.

\footnotetext{
1 Instituto Federal do Pará, Brasil. E-mail: sandrodantatagiba@yahoo.com.br.

2 Departamento de Engenharia Rural/Universidade Federal do Espírito Santo, Brasil. E-mail: anelisapeloso@hotmail.com.

${ }^{3}$ Departamento de Fitopatologia/Universidade Federal de Viçosa, Brasil. E-mail: fabricio@ufv.br.
} 